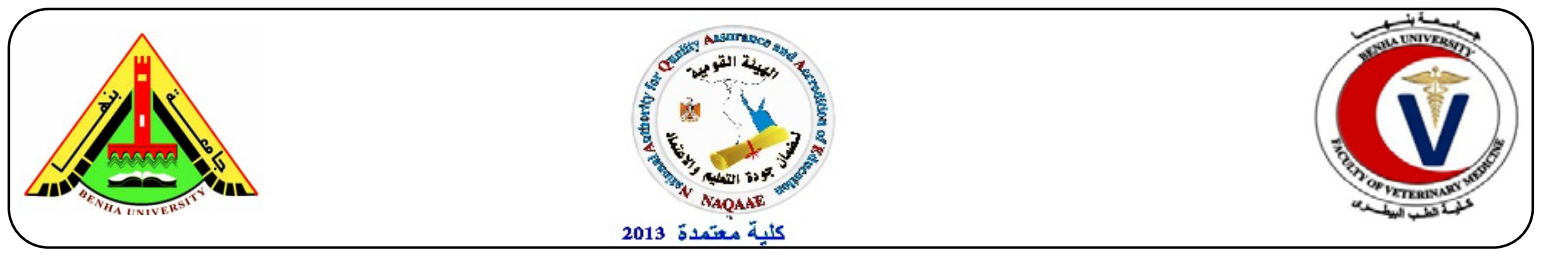

\title{
Molecular characterization of a recent Newcastle disease virus outbreak in Egypt
}

\author{
Gabr. F. El-Bagoury ${ }^{1}$, Ehab. M. El-Nahas ${ }^{1}$, Mahmoud. M. Abd-El-Monem², Mohamed. A. \\ AboElkhair ${ }^{2}$ \\ ${ }^{1}$ Department of virology, Faculty of Veterinary Medicine, Benha University. ${ }^{2}$ Veterinary Serum and \\ Vaccine Research Institute, Abbassia, Cairo.
}

\section{A B S T R A C T}

Newcastle disease (ND) is a highly contagious viral disease and is a continuous threat to the poultry industry worldwide. In the early months of 2014, several devastating ND outbreaks affecting broilers had been occurred in Sharqia province, Egypt. The fusion gene of the isolated Newcastle disease virus (NDV) was partially amplified by RT-PCR, then directly sequenced. The NDV isolates were found to have the motif 112RRQKRF117. This motif and the intracerebral pathogenicity index (ICPI) are indicative of the velogenic nature of these NDV isolates. Phylogenetic analysis showed that the new NDV strain belongs to the lineage 2 genotype II and is closely related to the Egyptian strain VRCLU/Giza/2009. Based on the high nucleotide similarity between our isolated NDV isolates and the Egyptian NDV strain, the origin of these recent NDV isolates might be from Egypt.

Keywords: NDV, ICPI, RT-PCR, Velogenic

(BVMJ-29(2): 303-308, 2015)

\section{INTRODUCTION}

Newcastle disease (ND) is one of the most serious infections of poultry. Outbreaks of virulent ND require an immediate reporting to the Office of International Epizootes (OIE) (Alexander, 1997). Newcastle disease virus (NDV) has a negative-sense, single-stranded RNA genome, belongs to the Avulavirus genus, within the family Paramyxoviridae, in the order Mononegavirales, and is designated avian paramyxovirus 1 (APMV-1) (de Leeuw and Peeters, 1999). The genome contains at least six major genes encoding the nucleocapsid protein (NP), phosphoprotein (P), matrix (M) protein, fusion (F) protein, haemagglutinin-neuraminidase $(\mathrm{HN})$ and RNA-dependent RNA polymerase (L) protein in the order of 3-N-P-M-F-HN-L5(de Leeuw and Peeters, 1999). NDV isolates are classified into two distinct classes (class I and class II) within a single serotype (Czegledi et al., 2006). Each class has been further classified into different genotypes; class I (night genotypes from 1 to 9) and class II (ten genotypes from I to X). Genotype VII (class II genotype VII) was firstly categorized into two subgenotypes: VIIa, which represents viruses that emerged in the 1990s in the Far East and spread to Europe and Asia; and VIIb, which represents viruses that emerged in the Far East and spread to South Africa. Later, the two subgenotypes of VII are classified into VIIc, $\mathrm{d}$, and e, which represents isolates from China, Kazakhstan and South Africa; and VIIf, g, h, and i, which represent African isolates (Miller et al., 2010). Based on the pathogenicity of NDV isolates in chickens,NDVs are divided into three main pathotypes: velogenic (high virulence), mesogenic (moderate virulence), and lentogenic (low virulence) (Alexander, 2000). Both mesogenic and velogenic strains are classified as virulent strains and can cause high morbidity and mortality rates in commercial poultry farms. 
In Egypt, NDV outbreaks are occurring frequently, and the rapid and accurate diagnosis of ND are essential. Therefore, the present study was conducted to isolate and molecular characterize NDV isolated from the recent outbreak in sharqia province, Egypt.

\section{MATERIAL AND METHODS}

\section{1. clinical Specimens}

Within two years of this study (January 2013 to December 2014), forty NDsuspected field samples (trachea, liver and brain tissues) were obtained from chickens flocks suspected to have ND in three broiler farms of Sharqia Province. Most sacrificed chickens had diarrhea, also showed nervous symptoms and respiratory difficulties. The specimens were grinded in phosphate buffered saline, $\mathrm{pH}$ 7.4, containing antibiotics of $(2000 \mathrm{U} / \mathrm{ml})$ penicillin, (2 $\mathrm{mg} / \mathrm{ml}) \quad$ streptomycin, $(50 \quad \mathrm{lg} / \mathrm{ml})$ gentamycin and $(1000 \mathrm{U} / \mathrm{ml})$ fungizone. After three cycles of freezing and thawing, the samples were clarified by centrifugation at $5000 \mathrm{rpm}$ for $10 \mathrm{~min}$ then the supernatants were collected and stored at $80^{\circ} \mathrm{C}$ until used.

\subsection{Virus isolation in ECE}

The supernatants were inoculated into 10day-old embryonated chicken specificpathogen-free (SPF) eggs via the allantoic route using $0.2 \mathrm{ml} / \mathrm{egg}$. The eggs were incubated at $37^{\circ} \mathrm{C}$ daily with candles for 5 days. Eggs showing embryonic death within $24 \mathrm{~h}$ of inoculation were discarded and considered non-specific, whereas eggs showing embryonic death after $24 \mathrm{~h}$ and remaining alive up to 5 days were chilled. Allantoic fluid from each of the inoculated eggs was harvested and tested for haemagglutination (HA) using $1 \%(\mathrm{~V} / \mathrm{V})$ chicken RBCs. The HA-negative samples were passaged two further times in SPFeggs, and the HA titer of the allantoic fluid was again determined. All HApositive allantoic fluids were further assayed for NDV using RT-PCR.

\subsection{RNA extraction}

The total RNA was extracted from $140 \mu 1$ of the HA-positive allantoic fluid as well as LaSota vaccinal strain as positive control and non-infected allantoic fluid as negative control using QIAamp Viral RNA extraction kit (Qiagen, USA). After lysis of the specimens, the mixture was transferred to a spin column according to manufacturer's protocol. The extracted RNAs were eluted in $60 \mu$ l elution buffer and stored at $-80{ }^{\circ} \mathrm{C}$ until further use.

\subsection{RT-PCR and sequencing of Fusion gene}

The RNAs were reverse transcripted using RevertAidTM first strand cDNA synthesis kit (Fermentas, Germany). The reaction mixture was carried out in a $20 \mu 1$ volume containing $5 \times$ buffer $(4 \mu \mathrm{l}) ; 10 \mathrm{mM}$ dNTPs $(2 \mu 1) ; 1001 \mathrm{M}$ random hexamer primers (1 $\mu 1) ; 20$ units RNase inhibitor (1 $\mu 1) ; 200$ units reverse transcription enzyme $(1 \mu \mathrm{l})$; nuclease-free water $(8 \mu 1)$; and RNA $(3 \mu 1)$. The RT reaction was composed of one cycle at $25^{\circ} \mathrm{C}$ for $5 \mathrm{~min}, 42{ }^{\circ} \mathrm{C}$ for $60 \mathrm{~min}$ and 70 ${ }^{\circ} \mathrm{C}$ for $10 \mathrm{~min}$. The hyper-variable region of $\mathrm{F}$ gene containing the cleavage site was amplified using degenerate primers as shown in Table 1. The PCR reaction was carried out in a 50-1l total volume containing 29 DreamTaq green PCR master mix (Fermentas, Germany) $(25 \mu \mathrm{l}) ; 10 \mu \mathrm{M}$ of each forward and reverse primers $(1 \mu 1)$; nuclease free water $(18 \mu \mathrm{l})$; and cDNA (5 $\mu 1)$. The PCR cycling profile was initial denaturation $1 \mathrm{~min}$ at $94{ }^{\circ} \mathrm{C}$ followed by 35 cycles of $30 \mathrm{~s}$ for denaturation at $94{ }^{\circ} \mathrm{C}, 30$ $\mathrm{s}$ for annealing at $55^{\circ} \mathrm{C}$, and extension at $72^{\circ} \mathrm{C}$ for $45 \mathrm{~s}$ and final extension at $72{ }^{\circ} \mathrm{C}$ for $10 \mathrm{~min}$. The amplified PCR products were electrophoresed in $1.5 \%$ agarose gel stained with ethidium bromide and documented using ultraviolet transilluminator. The specific bands were excised from gel and purified using EZ-10 Spin Column DNA Gel Extraction Kit (Bio 
Table 1 Sequence and nucleotide positions for primers of fusion gene

\begin{tabular}{llccc}
\hline Primers name & \multicolumn{1}{c}{ Sequence (5-3) } & $\begin{array}{c}\text { Nucleotide } \\
\text { position }\end{array}$ & $\begin{array}{c}\text { Amplicon } \\
\text { size }\end{array}$ & Reference \\
\hline APMV1-F-F & 5-ATGGGCYCCAGACYCTTCTAC-3 & $47-67$ & & $\begin{array}{c}\text { Seal et al. } \\
(1995)\end{array}$ \\
APMV1-F-R & 5-CTGCCACTGCTAGTTGTGATAATCC- & $557-581$ & 535 bp & \\
\hline
\end{tabular}

Table 2 Newcastle disease viruses used in the phylogenetic tree construction

\begin{tabular}{lccc}
\hline Isolate definition & Origin & Genotype (lineage) & GenBank accession \\
\hline NDV/Chicken/Giza/Egypt/MR0/2012 & Egypt & VIId (5d) & JX173098 \\
NDV/Ostrich/Ismailia/2010 & Egypt & II (2) & JN193503 \\
NDV/VRCLU/Giza/2009 & Egypt & II (2) & HQ455810 \\
NDV/chicken/Egypt/4/2006 & Egypt & II (2) & FJ969395 \\
NDV/chicken/Egypt/3/2006 & Egypt & II (2) & FJ969394 \\
NDV/chicken/Egypt/2/2006 & Egypt & II (2) & FJ969393 \\
NDV/Chicken/Egypt/1/2005 & Egypt & II (2) & FJ939313 \\
LaSota/46 & USA & II (2) & M24696 \\
Hitchner B1/47 & USA & II (2) & M24695 \\
BeaudetteC/45 & USA & II (2) & M24697 \\
Clone 30 & USA & II (2) & Y18898 \\
Mexico 468/01 & Mexico & V (3c) & EU518685 \\
BITPI87079 & Italy & V (3c) & AY135747 \\
Chicken/China/SDYT03/2011 & China & VIId (5d) & JQ015297 \\
Turkey/Israel/111/2011 & Israel & VIId (5d) & JN979564 \\
Chicken/Israel/174/2011 & Israel & VIId (5d) & JN849578 \\
Apmv1/Chicken/Jordan/Jo11/2011 & Jordan & VIId (5d) & JQ176687 \\
Chicken/Sudan/03/2003 & Sudan & VIId (5d) & GQ258670 \\
Chicken-2601-Ivory Coast-2008 & Ivory Coast & $(7 b)$ & FJ772466 \\
Avian-1532-14-Mauritania-2006 & Mauritania & $(7 b)$ & FJ772455 \\
Chicken-3490-149-Cameroon-2008 & Cameroon & $(7 b)$ & FJ772478 \\
& & &
\end{tabular}

Basic, Canada). The purified DNA was sequenced in an automated ABI 3730 DNA sequence (Applied Biosystems, USA). The obtained sequences were aligned by the Clustal W method using MEGA V5.05 software. The nucleotide sequences were compared with NDV sequences available in GenBank (Table 2). A phylogenetic tree of aligned sequences was constructed by Maximum Likelihood method. The deduced amino acid sequences were determined to detect the pathotype of isolated NDV. 


\section{RESULTS}

The use of degenerate primers for the fusion protein gene resulted in amplicons with the expected size of $535 \mathrm{bp}$. The deduced amino acid sequence of the isolate was compared with other strains of NDV.

These revealed that the amino acid sequence surrounding the fusion glycoprotein cleavage site of isolate NDV/chicken/Sharqia/Egypt/2014 carries the motif 112RRQKRF117 that is consistent with viruses of velogenic strains of the 2 lineage of genotype figure (1). Phylogenetic analysis of NDV/chicken /Sharqia /Egypt/2014 with other reference and vaccinal strains of NDV revealed that NDV/chicken /Sharqia/Egypt/2014 was related to the Egyptian strain VRCLU/Giza/2009 figure (2).

\section{DISCUSSION}

A great genetic diversity has been demonstrated among NDV strains based on phylogenetic analyses of partial or complete nucleotide sequences of the $\mathrm{F}$ gene that was reinforced by the wide use of DNA sequencing techniques in the last years (Miller et al., 2010). The amino acid sequence at the $\mathrm{F}$ protein cleavage site is a major determinant of NDV virulence, in Lentogenic viruses have a monobasic amino acid motif at the F cleavage site, $112 \mathrm{G}-\mathrm{R} / \mathrm{K}$ Q-G-R $\downarrow$ L117, and are cleaved extracellularly by trypsin-like proteases found in the respiratory and intestinal tract. Mesogenic and velogenic strains have a multi-basic amino acid motif at the $F$ cleavage site, $112 \mathrm{R} / \mathrm{G} / \mathrm{K}-\mathrm{R}-\mathrm{Q} / \mathrm{K}-\mathrm{K} / \mathrm{R}$ $\mathrm{R} \downarrow \mathrm{F} 117$ and can be cleaved intracellularly by ubiquitous furin-like proteases (Glickman et al., 1988). Analysis of the deduced amino acid sequence and phylogenetic analysis of the NDV F-gene of the strains NDV/chicken/Sharqia/Egypt $/ 2014$ proved that it to belong to class II, genotype II and carries the motif 112RRQKRF117 that is consistent with viruses of velogenic strains.

Our results agree with results of Hussein et al., (2013) who reported the importance of studying the genetic diversity of NDV field strains in different geographic regions of Egypt for understanding the genetic relatedness among NDV strains.

Also these results agree with that of Gould et al., (2003) who used genetic analysis as a predictor of the pathogenicity potential of NDV isolates and Mohamed et al., (2009) who reported that NDV genotype II has been reported to circulate in Egypt.

This confirming record of isolation and molecular characterization of this genotype in Egypt is thought to be spreading in Egypt through migratory birds, as previously reported (Mohamed et al., 2011).

There are some reports of wild birds becoming infected during outbreaks in poultry farms and a few reports of mortalities in wild birds, and in countries with widespread native chicken populations. The reservoir for NDV may well be such chickens, which could be possibly infected by wild birds and become a medium for intermediary spread of infection (Gilchrist, P. 2005).

In conclusion, NDV isolates circulating among chickens belong to class II, genotype II and carries the motif 112RRQKRF117 that is consistent with viruses of velogenic strains and associated with outbreaks in commercial poultry farms in Sharqia province. 


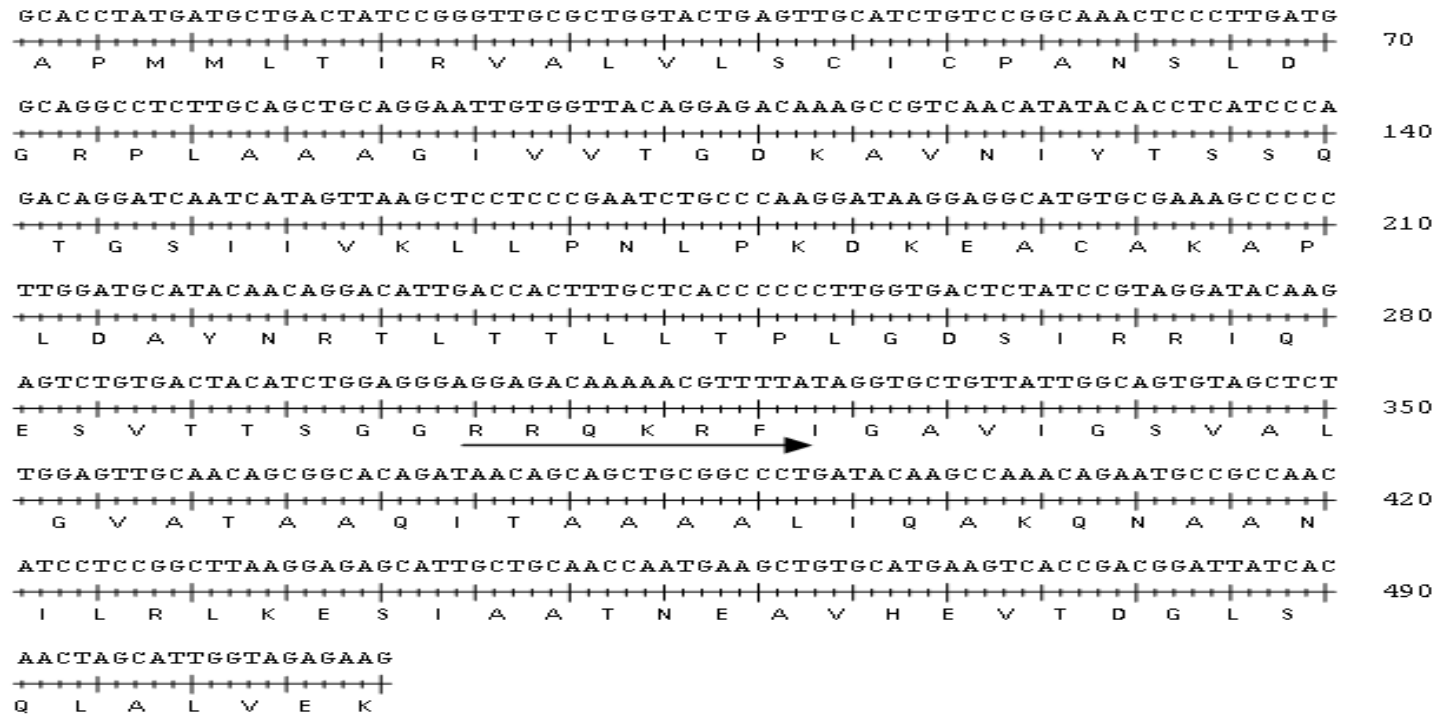

Fig. 1. Nucleotide and amino acid sequence of of the partial fusion gene fragment of Egyptian isolate (NDV/chicken/Sharqia/Egypt/2014), the arrow underline characteristic amino acid motif RRQKRF indicate velogenic strain.

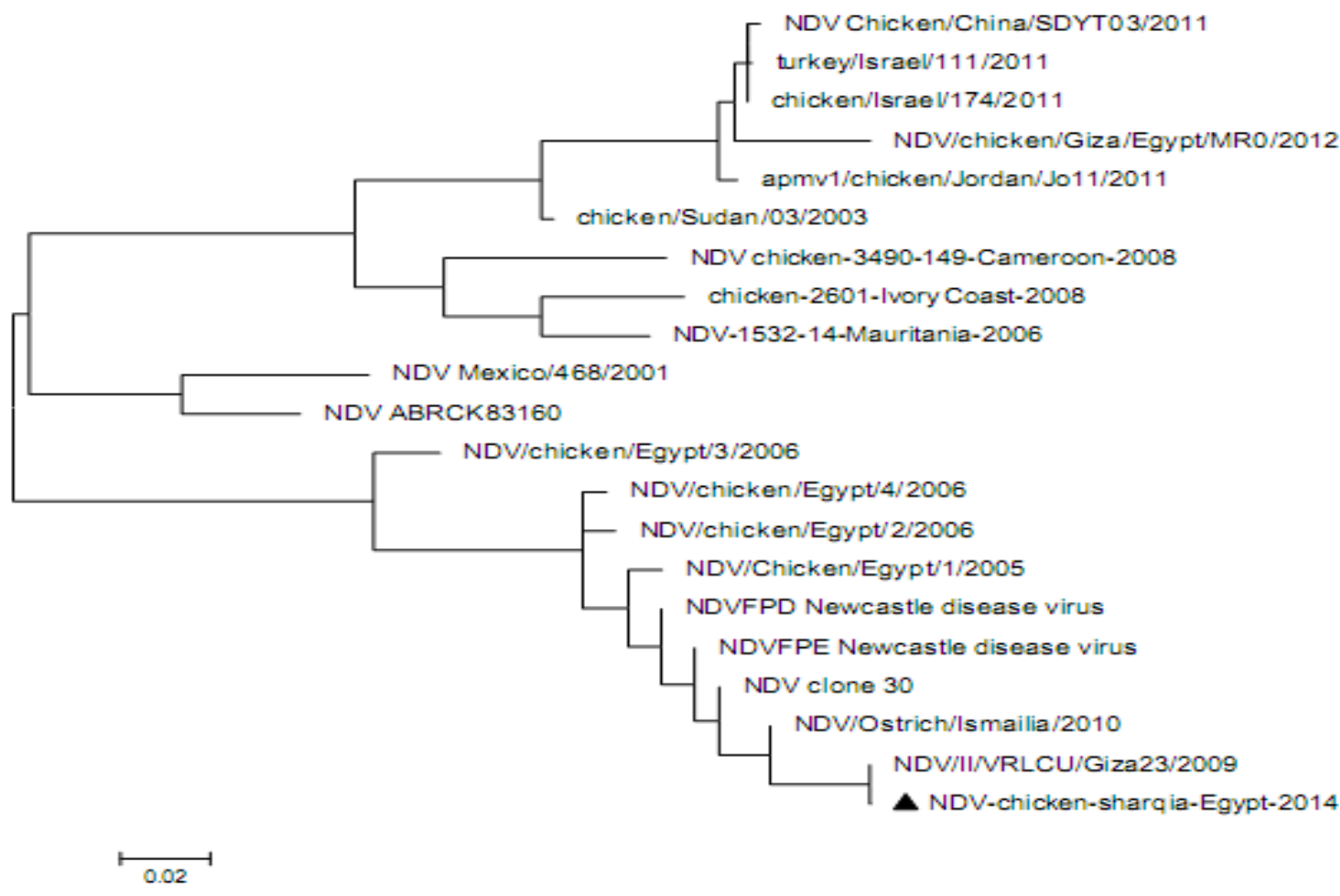

Fig. 2; Phylogenetic tree of the nucleotide sequences of the partial fusion gene fragment of Egyptian isolates (marked with solid triangle) and the references strains from GenBank using maximum likelihood method with bootstrap values for $\mathrm{n}=100$ replicates. 


\section{REFERENCES}

Alexander, D.J., 1997. Newcastle disease and other avian paramyxovirus infections In: Calnek, B.W., Barnes, H.J., Beard, C.W., Reid, W.M., Yoder, H.W., Jr. (Eds Diseases of Poultry, ninth ed. Iowa State University Press, Ames, pp. 541-570.

Alexander, D.J., 2000. Newcastle disease and other avian paramyxoviruses. Revue scientifique et technique (International Office of Epizootics) $19,443-462$.

Czegledi A, Ujvari D, Somogyi E, et al.: 2006, Third genome size category of avian paramyxovirus serotype 1 (Newcastle disease virus) and evolutionary implications. Virus Res 120:36-48.

de Leeuw, O., Peeters, B., 1999. Complete nucleotide sequence of Newcastle disease virus: evidence for the existence of a new genus within the subfamily Paramyxovirinae. Journal of General Virology 80:131-136.

Gilchrist, P. 2005. Involvement of freeflying wild birds in the spread of the viruses of avian influenza, Newcastle disease and infectious bursal disease from poultry products to commercial poultry.World's poult. Sci. J. 61, 198214.

Glickman, R., Syddall, R.J., Iorio, R.M., Sheehan, J.P. \& Bratt, M.A. (1988): Quantitative basic residue requirements in the cleavage activation site of the fusion glycoprotein as a determinant of virulence for Newcastle disease virus. Journal of Virology, 62:354-356.

Gould, A.R., Hansson, E., Selleck, K., Kattenbelt, J.A., Mackenzie, M., Della- Porta, A.J., 2003: Newcastle disease virus fusion and haemagglutinin-neuraminidase gene motifs as markers for viral lineage. Avian Pathol., 32:361-373.

Hussein H. A., Emara, M. M., Rohaim, M. A. 2013. Molecular characterization of Newcastle disease virus genotype VII $d$ in avian influenza $h 5 n 1$ infected broiler flock in Egypt. Inter. J. Virol., ISSN 1816-4900.

Miller, P.J., Decanini, E.L., Afonso, and C.L., 2010. Newcastle disease: evolution of genotypes and the related diagnostic challenges. Infect. Genet Evol., 10: 26-35.

Mohamed, M.H. Kumar, A. S. Paldurai, A. Megahed, M.M. Ghanem, I.A. Lebdah, M.A. Samal, S.K. 2009. Complete genome sequence of a virulent Newcastle disease virus isolated from an outbreak in chicken in Egypt. Virus Genes 39: 234-237.

Mohamed, M.H. Kumar, A. S. Paldurai, A. Samal, S.K. 2011. Sequence analysis of fusion protein gene of Newcastle disease virus isolated from outbreaks in Egypt during 2006. Virol. J. 8:237.

Seal BS, King DJ and Bennett JD 1995. Characterization of Newcastle-disease virus isolates by reverse transcription PCR coupled to direct nucleotide sequencing and development of sequence database for pathotype prediction and molecular epidemiologic analysis. J Clin Microbiol 33:2624-2630. 